\title{
Practical Applications of Agents and MAS: Methods, Techniques and Tools for Open MAS
}

\author{
Javier Bajo, Juan M. Corchado, Vicente Botti and Sascha Ossowski
}

\begin{abstract}
This paper presents a brief summary of the postproceedings of the special session on practical applications held in the framework of IWANN 2009. The special session was supported by the THOMAS (TIN2006-14630-C03-03) project and aims at presenting the results obtained in the project, as well as at exchanging experience with other researchers in this field.
\end{abstract}

Index Terms - Multiagent systems, Agent's technology.

\section{INTRODUCTION}

$\mathrm{R}_{\mathrm{s}}$ esearch on Agents and Multi-Agent Systems has matured during the last decade and many effective applications of this technology are now deployed. An international forum to present and discuss the latest scientific developments and their effective applications, to assess the impact of the approach, and to facilitate technology transfer, has become a necessity.

The Special Session on Practical Applications of Agents and Multiagent Systems (http://iwann.usal.es/mas), in the framework of the $10^{\text {th }}$ International Work-Conference on Artificial Neural Networks (IWANN 2009) provided a unique opportunity to bring multi-disciplinary experts and practitioners together to exchange their experience in all aspects of Agents and Multi-Agent Systems, especially those concerned with applications, methods, techniques and tools for open multi-agent systems.

The session intended to bring together researchers and developers from industry and academic world to report on the latest scientific and technical advances on the application of multi-agent systems, discuss and debate the major issues, and showcase the latest systems using agent based technology. It is a multidisciplinary discipline that may attract scientist and professionals to IWANN and to provide a different field in which to apply ANN based technology. It promotes a forum for discussion on how agent-based techniques, methods, and tools help system designers to accomplish the mapping between available agent technology and application needs. Other stakeholders should be rewarded with a better understanding of the potential and challenges of the agentoriented approach.

This special session was supported by the THOMAS research project (TIN2006-14630-C03-03), which aim is to

\footnotetext{
Javier Bajo is with Pontifical University of Salamanca.

E-mail: jbajope@upsa.es

Juan M. Corchado is with University of Salamanca.

E-mail: corchado@usal.es

Vicente Botti is with Technical University of Valencia.

E-mail: vbotti@dsic.upv.es

Sasscha Ossowski is with University of Rey Juan Carlos.

E-mail: sascha.ossowski@urj.es
}

advance and contribute methods, techniques and tools for open multiagent systems, principally in the aspects related to organisational structures. THOMAS is a coordinated project in which the University of Salamanca, the Technical University of Valencia and the University of Rey Juan Carlos cooperate to find new solutions in the field of the multiagent systems. This special session provides a framework to disseminate the results obtained in the project and to exchange knowledge with other researchers in the field of the agent technology.

This volume includes a selection of the best papers presented in the special session, focusing on the physical aspect of the agents and multiagent systems.

\section{THOMAS: METHODS, TECHNIQUES AND TOOL FOR OPEN MuLTIAGENT SYSTEMS}

The recent years technological evolution in the areas of Computer Technology and Communications (Internet, WWW, e-commerce, wireless connectivity, etc.) has given rise to a new computation paradigm: 'computation as interaction'. In this new paradigm, computation is something that occurs by means of and through communication among computational entities. Given this approximation, computation becomes an inherently social activity, instead of solitary, leading to new forms of conceiving, designing, developing and handling computational systems. An example of the influence of this point of view is the emerging model of the software as a service, as in the service-oriented architectures. In this model, the applications are no longer monolithic single-user applications, or distributed applications managed by only one organization, but rather societies of computational entities (components) that can be conceived as service providers. These components may not have been designed in a joint way or even by the same development team; they may enter or abandon different societies in different moments and for different reasons; and they may form coalitions or virtual organizations between themselves to attain their current goals.

The technology of agents / multiagent systems (MAS) has some characteristics that show its potential to support this new paradigm of computation as interaction, especially that of Open MAS. To satisfy the requirements of this new paradigm, we should provide the technology with the methods, agents, techniques, tools and infrastructures that support these new computational needs in a strong and efficient way.

Dynamic organizations of agents that self-adjust to obtain advantages from their present context are becoming increasingly important. These organizations might appear in dynamic or emerging societies of agents, such as the ones suggested by 
the Grid domains, Ambient Intelligence domains, or any other domain in which agents coordinate dynamically to offer compound services. Social factors in the organizations of multiagent systems are also more and more important to structure the interactions in dynamic and open worlds. Any infrastructure that supports the execution of multiagent applications in these contexts should be strong and efficient. New approaches are necessary to support the infrastructures evolution, and to facilitate their growth and updating in execution time due to the characteristics of these open environments.

Essentially, the THOMAS project comes up with two major lines of research:

Dynamism/Regulation: flexibility to permit the entrance and exit of agents, evolution of the organisational structure, coercive mechanisms, etc.

Heterogeneity: different types of agents with diverse capabilities, different run-time coordination mechanisms (requires semantic descriptions of capabilities or services), different devices (physical resources of the devices), different communication channels (wireline or wireless networks)

In this context, the THOMAS project defines development methods, standards, and platforms for the interoperability of agents that consider these requirements.

\section{Special Issue on Practical Applications of Agents and Multiagent Systems DetaILS}

This volume presents a selection of the best papers selected from those that were accepted for the 2009 edition. These articles capture the most innovative results and this year's trends: Multi-Agent Systems (MAS) Applications: commerce, health care, industry, internet, etc.; Agent and MAS architectures; Agent development tools; MAS middleware; Agent languages; Engineering issues of MAS; Web services and agents; Agents and grid computing; Real-time multi-agent systems; Agent-based social simulation; Security in MAS; Trust and reputation in MAS; Improving user interfaces and usability with agents; Information recovery with MAS; Knowledge management with MAS; Software Agents in Ubiquitous Computing; Agent technologies for Ambient Intelligence; Software Agents in Industry; Planning and scheduling in MAS; Agent Technologies for Production Systems; Service-Oriented Computing and Agents; Agents for E-learning and education; Mobile computation and mobile Communications. Each paper has been reviewed by three different reviewers, from an international committee composed of 15 members from 7 different countries. From the 17 papers accepted and presented in the special session, 6 were selected for this special issue:

In the first paper, Trigo et al. propose a multi-agent based simulation (MABS) framework to construct an artificial electric power market populated with learning agents The artificial market, named TEMMAS is materialized in an experimental setup involving distinct power generator companies which operate in the market and search for the trading strategies that best exploit their generating units' resources.

Gutiérrez and García-Magariño, in the second paper present a metrics suite for evaluating the communication of the multiagent systems. These metrics assist designers in detecting undesirable communication patterns in multi-agent systems, in order to improve their cooperative behavior..

In the third paper, Conte et al. present a paradigm for modelling and analysing Home Automation Systems, based on Multi-Agent System theory. A rich and versatile environment for Home Automation System simulation is constructed for investigating the performances of the system.

Rodríguez et al. in the fourth paper illustrate a case study in which the THOMAS architecture is applied in order to obtain a multiagent system (MAS) that can provide recommendations and guidance in a shopping mall. The paper demonstrates that THOMAS is made up of a group of related modules that are well-suited for developing systems in other highly volatile environments similar to a shopping mall.

In the fifth paper, Urra et al. study existing mobile agent platforms by analyzing if they are suitable or not in a mobile environment. They identify some key missing features in the platforms and highlight the requirements and challenges that lie ahead. With this work, they expose existing problems and hope to motivate further research in the area.

In the last paper, Serrano et al. present the development of an infrastructure to study highly complex systems of Ambient Intelligence (AmI) which involve a large number of users. The key ideas about the development of a multi-agent based simulation (MABS) for such purposes, Ubik, are given. The paper also extrapolates effective technologies in the development of multi-agent systems (MAS) to the field of MABS. In particular, the basis for the use of forensic analysis as a method to assist the analysis, understanding and debugging of Ubik in particular and the general MABS are set up.

\section{SPeCial IsSUE ACKNOWLEDGEMENTS}

We would like to thank all the contributing authors, as well as the members of the Program Committee and the Organizing Committee for their hard and highly valuable work. Their work has helped to contribute to the success of this special session. We also would like to thank the IWANN 2009 for giving us the opportunity of organizing the special session, for their help and support. Thanks for your help, the special session on practical applications of agents and multiagent systems wouldn't exist without your contribution. Finally, The Guest Editors wish to thank Professors Miguel Cazorla and Vicente Matellan (Editors-in-Chief of Journal of Physical Agents) for the publication of this special issue, which notably contributes to improve the quality of the special session and the THOMAS project. We hope the reader will share our joy and find this special issue very useful.

\section{ACKNOWLEDGMENT}

This work has been supported by the MEC TIN2006-14630C03-03 project. 